\title{
Surfaces
}

\section{Just Politics: Bill Reading's Impertinent Call}

\section{Valeria Wagner}

Volume 6, 1996

LES ÉCONOMIES DISCURSIVES DU SAVOIR ET DE LA CULTURE DANS LE SILLAGE DE L'OEUVRE DE BILL READINGS

THE DISCURSIVE ECONOMIES OF KNOWLEDGE AND CULTURE, WITH CONSTANT REFERENCE TO THE WORK OF BILL READINGS

URI : https://id.erudit.org/iderudit/1064855ar

DOI : https://doi.org/10.7202/1064855ar

Aller au sommaire du numéro

Éditeur(s)

Les Presses de l’Université de Montréal

ISSN

1188-2492 (imprimé)

1200-5320 (numérique)

Découvrir la revue

Citer cet article

Wagner, V. (1996). Just Politics: Bill Reading's Impertinent Call. Surfaces, 6. https://doi.org/10.7202/1064855ar
Résumé de l'article

Dans cet article, j'explique que l'impertinence est l'une des multiples stratégies mises en branle dans les écrits de Bill Readings pour désamorcer les metanarrations modernistes et leur implicite sujet universel. Mais si en rendant ces narrations impertinentes (non pertinentes) on peut " sauver » les événements de la totalisation narrative, il faut encore prendre le risque de rendre impertinente l'action elle-même par rapport aux événements. 


\title{
Just Politics: Bill \\ Reading's Impertinent Call
}

Valeria Wagner

Département d'Anglais

Université de Genève

Wagner@uni2a.unige.ch

Surfaces Vol. VI. 210 (v.1.0A - 08/10/1996) - ISSN: 1188-2492

Copyright for texts published in Surfaces remains the property of authors. However, any further publication should be accompanied by an acknowledgement of Surfaces as the place of initial publication.

\begin{abstract}
In this article I argue that "impertinence" is one of the main strategies at work in Bill Reading's writings to disempower modernist metanarratives and their implicit universal subject. But if rendering these narratives impertinent (irrelevant) can "save" events from their totalizing grasp, the risk remains of rendering action itself impertinent to events.
\end{abstract}

\section{RÉSUMÉ}

Dans cet article, j'explique que l'impertinence est l'une des multiples stratégies mises en branle dans les écrits de Bill Readings pour désamorcer les metanarrations modernistes et leur implicite sujet universel. Mais si en rendant ces narrations impertinentes (non pertinentes) on peut sauver les événements de la totalisation narrative, il faut encore prendre le risque de rendre impertinente l'action elle-même par rapport aux événements. 
How is a history a priori possible?

Answer: if the diviner himself creates and contrives

the events which he announces as possible.

(Immanuel Kant, "An Old Question Raised Again:

Is the Human Race Constantly Progressing?")

Although Bill Readings' work teaches its readers to be suspicious of "traditional" left wing politics, it does not go against its grain to qualify his writings as engagés, in full recognition of the militant connotations of the term.[ 1 ] Indeed, not only are Bill's writings about political issues, but they address the typically militant concern over the possibility of just politics, that is, a politics based on the possibility of justice for all, consisting in the practice of justice - - in short, a politics that would be political, just politics. It is in fact this very principle affiliating Bill's work to "left wing" politics which motivates his critique of the "redemptive politics"[ 2 ] characterizing most of the historical "left wing" tendencies, and which leads him to question, in particular, their models of political action and agency.

Very briefly, Bill calls "redemptive" all politics relying on the modernist metanarrative of development and assuming that the aim of politics is to lead society to its perfected state, at which point politics itself would reach its end. Such politics, Bill argues, are inherently exploitative, because they "promise a hereafter" which can justify the pains of today: "submit to your bosses in the factory, the home or the party now, and all will be well later on" (PW, xxiv). In so far as this kind of metanarrative understands the perfection of society as the absence of conflicts and the end of politics, it is not only exploitative, but also terroristic in its vision of a harmonious "all of us" that would be just in itself. This "all of $u s$ " is terroristic not only because it is an "all" which we should become, but also because, in order to enable the model of justice and politics of the perfected society to apply, it must be postulated in the present time as a "dormant" and universal "we" in all, which justice, as it were, actualizes, and which cannot be disavowed. The assumption of such universal "we", Bill argues repeatedly, "lights the way to terror even as it upholds the torch of human rights".[ $\underline{\mathbf{3}}$ ] Thus for Bill the attempt to conceive of a just politics requires the effort not to think of "all" as a universal category and, 
consequently, not to consider "justice" and "practice" in terms of the application of models of "hereafters". In his writings, the positive formulationof these nots is Lyotard's "paganism", characterized by an "attention to difference" (PPP, 186), a "form of attention, minor process of reading or listening" (PW, xxiii)[ $\underline{\mathbf{4}}]$ - subtle activities which in Bill's arguments become acts of resistance to modernist metanarratives, as well as practices of justice that Bill enjoins his readers to engage in.

In Pagans, Perverts or Primitives? Experimental Justice in the Empire of Capital, Bill's injunctions to his readers becomes a straightforward calling to "attend to difference"; an urgent and rather difficult calling (difficult to follow, to take into account), to which I am now responding with this article. The urgency and difficulty of this call are in fact not unrelated, as it is apparent in the last paragraphs of the article, where Bill concludes that

to struggle against ourselves, to attempt to think the multiplicity and diversity of culture without recourse to totalitarian notions of the universal, may be the best hope for avoiding total destruction in a world where the dream of consensus stands revealed as the nightmare of mutual annihilation...The problem of averting genocide demands a respect for difference... (186)

If we consider the prospect of "total destruction" seriously (and this does not go without saying), Bill's assumption that individuals can take measures to prevent it will certainly be welcome. But we may still find it difficult to establish concrete connections between our everyday behaviour and the genocide we are enjoined to avert. Indeed, it is easier to grant that we are all, whether or not in spite of ourselves, complicitous with the criminal acts of the Western societies of which we are members, than to undo this complicity and imagine ways to impede further crimes. And, while Bill's injunction to "attend to difference" and "to struggle against ourselves" functions in his argument as an indication of a "way" to avert genocide, it does not relieve his readers of the task of imagining what this struggling and attending could consist in. Bill's "instructions", we might feel, are not sufficiently instructive.

Their imprecision, however, is imposed by the nature of the danger that Bill addresses and, more specifically, by 
the composite nature of the agency responsible for genocide. For Bill presents "total destruction" as the consequence, not of the decision of specific people, but as the concrete instantiation of the logic of modernist metanarratives. Now, metanarratives do not, on their own, control events: as Bill relentlessly points out, "things happen" not only because, but also, surprisingly, in spite of and beyond their narrative scope - and not just "things", but "unpredictable resistances" (PW, xv). Metanarratives rule events in so far as they determine the behaviour of agents who can bring them to effect; but even the most totalitarian metanarrative will fail to affect the totality of agents, as it will fail to determine their behaviour completely. Metanarratives, I insist, are not self-sufficient, reality-producing machines. But they can be said to provoke events or to integrate within themselves events that they do not provoke, if the agency we grant them is understood as an expression of the fact that metanarratives are not themselves controllable. They are not controllable in the sense that everything under their narrative scope will submit to their logic, and everything that can be formulated according to their logic will fall within their narrative scope. In this sense metanarratives cannot be stopped, they can only be rendered ineffective. Thus genocide, the logical extreme of modernist metanarratives, can only be avoided, and this only if the metanarratives themselves can be circumvented. This, however, is not physically feasible: a metanarrative cannot be escaped, particularly those specializing in "hereafters" and "elsewheres". Only that which is irrelevant to the metanarrative is free from its logic, and vagueness precludes relevance. Bill's vague instructions, in fact, do more than preclude relevance: I want to argue that they are impertinent, and that their impertinence is meant not only to avoid the narrative scope of modernism, but to render modernist metanarratives themselves impertinent - to "us", to what happens, to what could happen.

The recommendation to "attend to difference" is in itself, from the perspective of modernist metanarratives, impertinent, in so far as it does not require the levers of a "hereafter", an "elsewhere" or a "better same" that impel modernist metanarratives. These "levers" can easily integrate into modernist plots all demands for and discourses on change, the possibility of which has doubtless been a fundamental presupposition in "left wing politics". But change implies a temporal movement from one state to another which cannot be fully theorized (how is it that things change, that change comes about? For all our conceptual apparatus, changes still appear to be given, rather than done...) and which 
lends itself to spatialization by modernist narratives - the movement becomes a path to follow towards the better elsewhere or hereafter. Change, in this sense, is a very pertinent concept for modernist metanarratives because it pertains to their functioning. Difference, instead, is only pertinent to modernist metanarratives in relation to identity and articulated as an "else" functioning to distinguish identities. Understood as the present form of change, it has no temporal or spatial gaps to yield to, and to be pertinent for, modernism: difference takes place here and now, while attending to it is a constant activity, or at least one that has no ending, has no end other than itself - indeed the difference to be attended to cannot be projected, willed, or anticipated, for then it is not difference anymore. Neither can it be done or made, unlike change in modernist metanarratives: it must be attended to, that is, noted, remarked, and waited upon. All this renders modernist narratives impertinent to difference, not relevant to the activity of attending to it and ultimately inoperative with regards to it. But it may well also render Bill's calling impertinent to us, readers, in so far as "attending to difference" cannot be described or signalled (it is not a project) and cannot be linked to specific concerns and actions - the pertinence of "attending to difference" to "averting genocide", for example, is not immediately apparent and certainly not direct.

Bill addresses the potential irrelevance of his call to his readers when he urges them to "explode the indifferent domination exercised by the consensual 'we'" in Pagans, Perverts or Primitives? This, he specifies, is not desirable "simply" to do justice to those communities which, like the Aborigenes of Herzog's film, resist inclusion into "our" common humankind and are thereby threatened to disappear - this would be a "humanist" argument, based on the universalizing impulse of modernist

metanarratives. The point would not be to "save" the Aborigenes, but to do justice to ourselves, bound as we are by our "own" metanarratives to suppress all dissemblance to "ourselves" in order to achieve a resemblance to "ourselves":

Ceasing to think community in terms of a universal "we" gives us the chance to relinquish our enslavement to our own power, to transform a culture in which we only feel ourselves to be "men" in so far as we silence what we cannot understand. (186) 
Punctuated as it is by the prospect of "total destruction", abandoning the power of our enslavement appears as a necessary step to bypass the ultimate form of indifferentiation of cultures and communities that is their physical elimination, of which our disembodiment into a universal "we" woud be but a preamble. He thus points out that it is in our interest to "attend to difference", as we are under the effects of the modernist metanarratives we bring to effect, and, as long as we fail to distinguish between the metanarrative universal "we" and us, the non-universal agents that bring metanarratives to effect, we inevitably contribute to their realization. The struggling "against ourselves" thus appears as a pertinent one, comparable in its appeal to guerrilla struggles and strikes.

It is not easy, however, to actually make the distinction between the we and the "we", as my encumbering use of italics and inverted commas demonstrates. The "struggle against ourselves" can certainly not be staged as a struggle between the "real" and "true" we and a "false" "we" in which the former would triumph over the latter: there are simply no such two entities. A nonmetanarrative we is in a sense presupposed by Bill's appeal to "struggle against ourselves" (for how else could such a struggle be motivated?); the we that could integrate "the multiplicity and the diversity of culture without recourse to totalitarian notions of the universal" (PPP, 186), the we of members of such a multiple and diverse community. This we, clearly, has instantiations, just as "things happen" and "unpredictable resistance occurs", but they are not obvious (the difference between "we" and we could not be pointed at). They cannot, moreover, be described, insofar as the attempt to determine what the we of a community that would respect multiplicity and diversity is like, would have to rely on the political terms available to "us", which only enable the thought of an ideal, universal community, a "city on a hill" (PPP, 185). Thus the we must remain indeterminate, or determined only as the we that can "listen" for instances of difference-respecting communities in events that resist explanation within modernist metanarratives. "Struggling against ourselves" and "ceasing to think in terms of..." (which are, thus formulated, impossible tasks), would accordingly consist in the practice of the us involved in the activity of listening and attending to difference. We remain, however, within the vagueness imposed by the attempt to "explode" the modernist metanarrative: the struggle for "freedom" can only be recounted with reference to that from which freedom is wanted, but the 
freedom in question cannot be accounted for in the terms of the metanarrative which defines it. There are no alternatives to modernist metanarratives other than or prior to that of rendering them impertinent, at which point difference (and not another world) "begins".

At this point, and hoping that I have not rendered Bill's argument too unjustly, the vagueness which made it seem difficult to follow Bill's "instructions" can be said to be a powerful weapon to paralyze modernist metanarratives and thus preserve the possibility of just politics. Let us return now to the urgency of Bill's calling, and appose it to the urgency readers may feel with regards to ongoing injustices rather than to an impending world genocide. The latter may well be avoided by our daily practice of attention to and respect for difference, but it is not clear how this policy of avoidance coud be an appropriate response to the former, or indeed, whether it does or should respond to "immediate" injustices at all. In other words, if our attending to difference is capable of incapacitating or rendering impertinent the modernist narratives that promote the kind of injustices Bill argues against, how does this affect specific cases of injustice, now? Is the kind of justice demanded, now, by those in situations similar to that of the Aborigenes of Herzog's film, the kind of justice which attending to difference is a practice of? Bill does not address these questions directly, but we can glimpse an answer to them in the implications of his reading of the court case in Herzog's film Where the Green Ants Dream, in which the "universal law of the white man" is shown attempting and failing to "take note of the Aboriginal rights" (PPP, 178).

Very briefly, the dispute brought to court is between an Aboriginal community and a mining company, and it is about land, of which both parties have completely different understandings and with regard to which their practices oppose each other. The Aborigines must preserve the Land, from which they are not themselves dissociable; in this particular instance, they must preserve it from the mining company, which treats it as a commodity, and purports to mine it. The court needs proof of the Aborigines' historical rights over the land, but cannot recognize the validity of those the Aborigines bring to court. Ultimately, the Aborigines lose the case because they do not speak the language of the white man. Bill focuses on the fact that "the injustice done to the Aborigines is not the effect of a biased white man's law" - "the judge is a kindly old man", who sympathizes with the Aborigenes - but the "effect of the very fairness of the white man's law, its blank, bleached, abstract 
humanity", which in its pretension to apply to all, silences most:

The Aborigenes are killed with kindness, by the assumption that they are the same kind of people as the white Australians; they are silenced by the very fact of being let speak (PPP, 180).

Herzog's film would convey the injustice of this silencing, not by taking issue with the court's verdict and revindicating the land for the Aborigenes, in their stead, but by attempting to do justice to the dispute that is silenced by "the white man's law". The film, Bill argues, "does not represent an other so much as bear witness to an otherness to representation, a différend, and could be considered as "an attempt to negotiate with the terms of Lyotard's call for quasi-aesthetic experimentation as the grounds for doing justice" (176).

Bill's insistence on the structural nature of the Aborigines' silencing rules out the possibility that a "better" judge, if not "kindlier" at least more receptive to the terms of the dispute, could have opened the legal procedure to the Aborigines' discourse, for this would imply challenging the fundamental assumptions of "the white man's law": that "we" are all literally equal, and that all discourses can be translated into the universal and thus neutral language of law. Insofar as it is vain to hope that institutions will shed their structural universalism, we cannot rely on them to empower our attention to difference and provide the link between this practice of justice and current cases of injustice. Rather, it seems that, just as we must "explode" the universalist "we" with our attention to difference, so must we "explode" the institutions that function according to this "we" - by doing without them, for example. Thus Bill suggests that the Aborigines' "mimetic sacrifice" at the end of the film - the tribal elder and an Aboriginal expilot fly off in an ant-like plane, "apparently crashing in the mountains" (PPP, 176) - may well be a way of avoiding the end of the world that was to ensue from their failure to preserve the Land by keeping the land. Whether this is the case or not, "the film does not explain", Bill tells us, just as he does not explain to us, his readers, whether or not our attending to difference will prevent the end of our world. But Bill's injunction to "explode the indifferent domination of the 'we'", echoing the "apparent" crashing of the ant-like plane, can be understood as a sign of his belief in the efficiency of "mimetic sacrifices". 
I should stress that Bill is not just saying that the injustice done to the Aborigenes is inevitable given the "white man's law" silencing structures. He is making a stronger point: that the kind of justice the "white man's law" can do is unjust in itself, in its assumption that the claims and idioms (PW) of both parties are commensurable, and that they can be translated to the universal language of humanism to be measured against each other. Thus, even if the court had ruled in favour of the Aborigines', it would still have been unjust: "'We' have no way of saying who is right here, the mining company or the Aborigines. No "we" can pronounce once and for all on their dispute "(PPP, 185). From its universalist stance, the court can only exercise injustice. The signs of Bill's belief in mimetic sacrifices should consequently be taken seriously - albeit not too literally for justice can only be done by bypassing "the white man's law", in terms that it can neither judge nor misjudge:

All we can do, and it is a very difficult task, is to try to tell another story, after these two, one that doesn't seek to synthesize or assimilate them but to keep [the] dispute and the difference an open question, that avoids the injustice of victimization, that doesn't speak with a "we". This does not mean resolving the dispute within the terms of Western rationality but preventing its suppression, keeping the difference in question (PPP, 185).

Once again the only option open to us is to "preserve" the possibility of justice by adopting a policy of avoidance of modernist metanarratives, a discourse that would not pertain to them and would not mobilize the universal "we" and its concurrent injustices. And, once again, as earlier with respect to Bill's readers, the question of the pertinence of such a policy can be raised: how would telling this third story pertain to either mining company or Aborigenes? What can telling this third story $d o$, if not now, then as soon as possible ? And if the telling of it does justice to the conflict, how can doing justice to their claims be envisaged? And if there is no universal model of justice, is it unjust to rule in favour of one party, and am I a universalist criminal if I say that the mining company should fry in hell and that the Aborigenes should have the necessary land to preserve their Land?

With these questions I am doubtless venting a certain degree of frustration, stemming less from the 
uncertainty or indeterminacy of Bill's calling than from the certainty with which it discards prevailing political and judiciary channels of action. My sense is that these, given the institutions in power now, cannot be universally dimissed to avoid injustice, because they cannot be bypassed to do justice - they are, as it were, in the way of justice. In other words, avoiding injustice is not necessarily doing justice, although it may be in itself a just procedure. In the case of the Aborigenes' demand for the land, for example, it is clear that to find a manner of preserving the Land that would not involve the land and would consequently spare them the conflict with the mining company that would in turn spare them an involvement with the Australian Republic, would also spare them the injustice of the court treatment of their case. But they would still have no recognized rights on the land, and would thus still be unable to preserve the Land through the land - an inability which, in the long run, will certainly not be compensated by mimetic sacrifices. I am arguing, ultimately, that given the structures in place at the present time, there is a sense of justice that can only be done by them, and that this sense of justice is not in itself unjust. I am thus arguing that, however universalist the modernist metanarratives are on which prevailing institutions model themselves, not only do they not universally do injustice, but they have it in their power to do justice. Let me develop these points through an exemplary case in which the issue of the land and the Land emerges clearly, articulating with urgency the question of the pertinence of response to demand.

Some years ago (9 October 1988) the Argentinian newspaper Calrín published an interview with a Mapuche Indian from the indigenous reserve of RukaChoroi, in the province of Neuquén. The interview took place in Mapuche, which the interviewer Nahuel Maciel obviously speaks fluently, having actually lived in that reserve and with the Mapuche Kalfuqueo's family when he was a child. Here is what Kalfuqueo (who was at the time 91 years old) says in reply to the interviewer's question, "what would you say to politicians?":

I am grateful for your questions, and I hope someone will be grateful for these answers. With you we can talk confidence and respect. With you I can listen with the eyes and talk with the hands. Now, to the señor politician, I would tell him to read my answers again, my written words, and to know the words of other Mapuches because there are Mapuches in many places, not only in Neuquén, but also in 
Salta, Chaco, Jujuy and other places. They have the same problems, the words will almost be the same. [I would tell] the politician not only to listen, but to come and see too. I do not beg for anything, justice cannot be begged for. Justice must be offered. If one does not offer justice, one is unjust. One is also unjust when one does not do anything for justice. I will not learn letters now, that is why I value the word a lot. These are the words of a Mapuche, a man of the Land, who presently has almost no land. Here, in the reserve, one lives as in a henhouse, one is surrounded by wire and every once in a while the master's hand arrives and gives us some grains to eat. But neither I nor anybody else wants to live in a henhouse. I want to be like a bird that flies in the air, but to be free I need land. There is no freedom without land. Now there are many governments, there is the government of the municipality, of the province, and of all the provinces together. Many governments and little justice. If you, who are a politician, want to be just, you should begin soon, because if you waste too much time and do not work soon, by the time you make up your mind perhaps I will no longer exist.[ $\underline{\mathbf{5}}$ ]

Kalfuqueo can obviously speak for himself, and knows very well whom to address. Indeed, he is not speaking to us, readers of this issue of Surfaces, and this for very obvious reasons: he wants something to be done for the Mapuches, which the Mapuches cannot do for themselves, and he wants this to be done now. What he wants is land, for he is a Mapuche, a man of the Land. He does not confuse the land he demands with the Land he is a man of. He does not ask for Land, or for freedom: these are for the Mapuches to preserve, not for politicians to provide. But he states clearly: to be free, to be of the Land, we need land. And this is a concrete demand made to the politician, stated in terms the politician can understand: land, not a henhouse. The quantitative and qualitative differences between "land" and a "henhouse" are, of course, to be discussed. This is why Kalfuqueo wants the politician who wants to be just to come and see and hear, instead of sending his master's hand to give. The politician, whether or not of Western rationality, can understand as much: the reserves are like henhouses, the Mapuches need more land. 
There is no question of incommensurable discourses here, as long as the politician and the Mapuche do not pretend to understand each other fully. And this is not the case: there is neither need nor demand for total understanding. There is one issue for politicians to understand, and this is the demand for land: they know what this means, and even the most obtuse of them knows that not to respond to this demand is to let not only Kalfuqueo but the Mapuche, as a physical people, die. If in the course of the conflict between the municipal or provincial government and the Mapuches, the latter are silenced, it is because the people who have it in their power to respond to their demand do not want to listen to them, and not because the Mapuches' discourse is alien to the discourse of politicians - although, to be sure, their discourses are different. Doing justice to the dispute between the different instances of the Argentinian government and the Mapuches would be, in this particular case, a criminal waste of time, and would from the outset serve the interests of the governments: indeed, in this case, leaving the "dispute an open question" is exactly what the politicians do, with the probable consequence that Kalfuqueo will have died surrounded by wire. As for "telling another story", it would only seem a pertinent thing to do if telling it could grant the Mapuches more land. Attending to the Mapuches' difference is not, here, tantamount to keeping the question of the dispute open: in this case, respect for difference demands that the conflict be resolved, in favour of the mapuches. Whether it is resolved by politicians, institutions, or the intervention of international organizations and in the name of human rights, only matters to the extent that some solutions are better - - more appropriate to the situation - than others.

But on what grounds am I saying all this? What is my basic assumption here? To be sure, I am assuming that Kalfuqueo's demand is just: that it demands justice and that doing justice to it consists in granting the Mapuches the land they need. But this is not so much an assumption as a repetition of what Kalfuqueo is saying. His demand is just because "nobody wants to live in a henhouse", and to accept this I do not need to rely on a universal human nature, but only on a kind of principle of "propriety": as long as a people do not identify with hens or with the hens' way of life, then a henhouse is not an appropriate habitat for them. Now, if Kalfuqueo's demand is just, then justice should be done to it because justice is by definition offered where there is the just demand for it. And here I am assuming that justice is desirable, rather than injustice: Bill assumes this too - is 
it an unjust assumption? No, because it would not do injustice to anyone. Still, am I not arguing in the name of universal human rights? I could do this, because the concept of "human rights", like all concepts, is not in itself absolute and can be put to different uses, for different causes - it could help the Mapuches win their case. But I don't think I need to believe in a universal, common human nature to take the Mapuches' side: I can be convinced by their case, once I have heard it - had I not heard it, I would not want justice for them. The important factor here is that I am taking sides, I am biased in favour of the mapuches, and this implies neither universalism nor injustice. If the universal "we" Bill argues against pretends to be just $a$ priori and without involvement, I argue for justice for the Mapuches and because I take sides with them. In this sense Kalfuqueo is right to address politicians, and not judges, for the justice he demands is of a political order, and in this sense he is also calling, like Bill, for just politics.

Regardless of its methodological value, the juxtaposition of Kalfuqueo's and Bill's call has the merit of foregrounding the question which has come up once and again in my discussion of the "impertinence" Bill argues for: how can "attending to difference" and "telling another story" be pertinent responses to specific demands for justice? If, as I have argued with Bill, impertinence is a disarming weapon against modernist metanarratives, does it not risk rendering particular demands for justice impertinent as well? To what, and whom, does Bill's call pertain? These questions imply, in a sense, a leap from theory to practice that Bill does not make in the article on which I have focussed - a leap, moreover, which he did not have to make. In this sense, I may well have been "mining" his argument for "maxims" in my attempt to respond to his call: I have been asking how we can attend to difference, and what difference it makes to do so. In so far as I have asked his argument to respond to the urgency of the Mapuches' call, I may have created a disagreement which he could have easily dispelled by expanding or clarifying his points. But then, maybe not: maybe the urgencies of Bill's and Kalfuqueo's call cannot be responded to in the same way - maybe they do not speak to each other. Let me then conclude this article addressing this "maybe" with yet another story, which could play the role of the "third" story in Pagans, Pervert or Primitives? and do justice to the two calls. It is about an attempt to set up a "community under a horizon of dissensus" (PPP, 184), in view of creating the conditions to deal with, and even resolve, conflicts. I think Bill would have enjoyed it. 
The story goes that in the years 1983 and $1984 \mathrm{Mr}$. Thomas Sankara,[ $\underline{\mathbf{6}}$ ] new president of Burkina Faso, decided that it was necessary to assemble the people in mass organizations, so as to represent their different interests and demands. So the women got together and elected delegates, the Catholics got together and elected delegates, and so on. But when it came to the Muslims to get together and elect their delegates, the different factions of the community - Sunites, Shiites and Sufis could not agree to be represented jointly. In the past, the different governments had always played these factions against each other: either the sunites had been addressed as the representatives of the whole Muslim community, or the Shiites had been addressed as the whole community, but they had never before been addressed as a community to be represented in its differences.

Seeing that they did not come up with a joint committee, Sankara called the Shiite, Sunite and Sufi representatives to a meeting at the presidential building, to find a solution with them. They discussed for hours, each faction reasserting its position and reformulating its arguments: they still thought they had to fight against one another to secure the position of exclusive representation of the Muslim community. This is how they had been led to function in the past. So the discussion went round and round, and eventually Sankara left the room in despair and irritation, locking the Muslim delegates in. They were thus left to come to terms with each other on their own, without the mediating presence of Sankara, without an external instance that could take a decision in favour of one or other party, and without the possibility of leaving the situation unresolved.

After a long while, Sankara came back and asked the immured delegates whether they had come up with their committee: the delegates laughed, they had no answer. Sankara told them that they would remain locked in until they came up with the representatives of the Muslim community, and left again. When Sankara came the second time, a very long while later, the three factions had come to an agreement, and had elected their delegates to the committee representing the Muslim community.

If politics is "the attempt to handle conflicts that admit of no resolution, to think justice in relation to conflict and difference" (xxiv), as Bill puts it in his Foreword to Lyotard's Political Writings, Sankara's "solution" to the 
enmities of the Muslim community could be read as yet another instance of silencing a conflict by recourse to political representation. But the story does not quite correspond to the political model, or procedure, the terroristic basis that Bill joined Lyotard to denounce. There is doubtless an element of "force" in Sankara's move of locking the conflicting parties together until they agreed to represent themselves as a community, but what force imposes in this case is the realization that a community need not be understood as devoid of conflict: indeed, the gathered parties here are in conflict, and they are a community. Moreover, it is because they are a community in conflict that they should cope with the conflict as a community, and in their own terms.

Accordingly the conflict over representation is "resolved" in Sankara's absence.

The story does not tell what happened inside the closed room, so I will speculate. It is improbable, given the power balance between the parties that the closed room sets as a starting point, that "the reconciliation" between the parties would have taken place "in the idiom of either one of them" (xxiii). The story rather insists on the decisive role of the physical factors of time and confinement: the delegates of each faction spent a considerable amount of time together, all equally exposed to fatigue, heat, thirst, and the like, and generally confronted the situation of an inevitable cohabitation, experienced rather crudely within four walls. In this sense, it is easier to imagine that a certain complicity among the delegates (they laugh when Sankara comes to check on their discord), spurred by the circumstances, provided new terms ("idioms") to measure their conflict, than to imagine that one party somehow "won" over the other two and imposed its own terms of negotiation.

What we have at the end of the story is dissensus integrated in a political structure in order to adress the conflicts which this dissensus generates. The dissensus is not abolished, but represented - in order to solve conflicts, as they surface. Whether this actually happened or not, I cannot say:[ $\underline{7}$ ] this is an unfinished story. 


\section{NOTES}

1. I do not say this to "save" Bill's political honour, but to point out what is, in my view, the crucial question raised by his reflections on politics.

2. See Bill Readings's "Foreword" to Jean-François Lyotard: Political Writings. Trans. Bill Readings and Kevin Paul Geiman. Minneapolis: University of Minnesota Press, 1993. Henceforth referred to as "PW".

3. Bill Readings, "Pagans, Perverts or Primitives? Experimental Justice in the Empire of Capital". In Judging Lyotard. Ed. Andrew Benjamin. London: Routledge, 1992, 186. Henceforth referred to as "PPP".

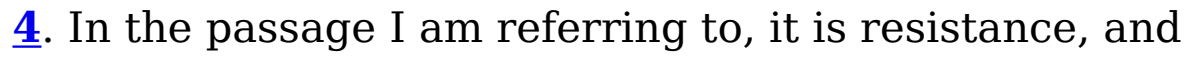
not paganism, which is actually qualified as "a form of attention, a minor process of reading or listening". In Bill's writings, however, Lyotard's "paganism" is characterized in terms similar to Lyotard's "resistance", or to the oikos discussed in "Privatising Culture: Reflections on Jean-François Lyotard" (in Angelaki 2:1, 1995, 23-29). Thus "the privacy of the oikos " only "requires...an exercise of listening, an exercise that is both difficult (complex) and simple (direct)" (28).

5. This is my translation from Spanish. The graphic distinction between Land and land is made by the interviewer.

6. Thomas Sankara became president of Burkina Faso in August 1983, through a coup-d'état which the population supported and eventually took on revolutionary dimensions. I heard this story from Raoul Ouedragoudo, who was in Burkina Faso, his native country, at the time the story recounts.

7. Thomas Sankara was assassinated in October 1987, and the political reforms he carried out were to a large extent dismantled.

Accueil Surfaces | Table des matières | Recherche Surfaces Home Page | Table of Contents | Search

PUM | Livres | Revues | Publications électroniques | Vente et distribution 